\title{
Spontaneous gastric perforation: is it really common?
}

\author{
Imran Hashim ${ }^{1 *}$ D, Nabila Talat', Asif Iqbal ${ }^{1}$, Muhammad Saleem Choudhary', Naveed Haider ${ }^{2}$, Sajid lqbal Nayyer ${ }^{1}$, \\ Muhammad Sharif ${ }^{3}$, Arslan Raza Wasti ${ }^{4}$ and Sarfraz Ahmad ${ }^{5}$
}

\begin{abstract}
Background: Neonatal gastric perforation (NGP) is a rare, serious, and life-threatening condition which needs early recognition with prompt intervention for better prognosis. Its etiology is not yet well established, but multiple speculations have been put forth for its etiopathogenesis. Few most considered are traumatic, spontaneous, or secondary to inflammatory process like necrotizing enterocolitis. This study describes the etiological and prognostic factors for patients with NGP in our experience at a single center.

Results: A total of 46 neonates were included. Male gender predominated with M:F being 1.7:1. Most $(n=36)$ neonates presented within 10 days of life whereas 8 neonates presented within 15 days. At presentation, gas under diaphragm was the most common radiologic finding in 25 (54.3\%) neonates. On exploratory laparotomy, it was found that greater curvature was involved in maximum number of cases $(n=27)$, followed by lesser curvature and anterior and posterior walls of the stomach. Most of perforations were within 1-5 cm in size. Gastrorrhaphy was done in all cases, and in two cases, feeding jejunostomy was done along with repair for feeding purpose. Finally, spontaneous NGP was diagnosed in $30(60.8 \%)$, and NEC patches on other parts of the intestine were seen in 11 patients. Postoperatively, 28 neonates developed complications in the form of sepsis $(n=13)$, wound infection $(n=$ $10)$, and burst abdomen ( $n=5)$. Regarding clinical outcome, 27 (58.7\%) were discharged from the hospital whereas 19 (39.3\%) patients died.
\end{abstract}

Conclusion: Our results show that spontaneous NGP is most commonly associated with NEC in our population, usually affecting the greater curvature. We observed a high mortality rate; however, good ICU care may improve the survival.

Keywords: Spontaneous gastric perforation, Neonate, Etiological and prognostic factors

\section{Background}

The first case of gastric perforation in neonates was reported by Siebold in 1825 whereas first survival of gastric perforation repair was reported in 1950 [1]. Among perforations of the intestine in neonates, the neonatal gastric perforation (NGP) has been reported in 7\% with poor prognosis and significant mortality [2, 3]. Prematurity, asphyxia neonatorum, birth stress, aggressive

\footnotetext{
* Correspondence: deardrimi2002@yahoo.com

${ }^{1}$ Department of Pediatric Surgery, The Children Hospital \& The Institute of Child Health, Lahore, Pakistan

Full list of author information is available at the end of the article
}

respiratory resuscitation at birth, anatomic pathologies causing gastric outlet obstruction, and few associated congenital anomalies have been reported to be the most important factors causing NGP in the literature [4-8]. The association of NGP with factors like male gender, metabolic acidosis, prematurity, or low birth weight claimed even worse prognosis $[9,10]$.

Many recent studies tried to elucidate prognostic factors, but no definite correlations were concluded, so prognostic factors remain as yet controversial. The common identifiable sign is abdominal distension that is mostly associated with shock. Early detection of such cases is important as it was found to improve mortality 
and morbidity of these neonates. In this study of single tertiary care unit conducted over 3 year's period, we describe our experience of clinical findings, management, and outcome in neonates with NGP at a single center.

\section{Methods}

Formal institutional ethical approval was sought for this prospective study. During a 3-year period from June 2015 to June 2018, a total of 570 neonates (within 30 days of life) presented in neonatal emergency with diagnosis of pneumoperitoneum. We included 46 patients with NGP into this study which reflects $8 \%$ of total intestinal perforations. Demographic details like gender, age of presentation, gestational age, birth weight, mode of delivery, presence of neonatal asphyxia, main signs and symptoms, gastric tube insertion and mechanical ventilation before the onset of gastric perforation, associated perinatal risk factors, associated congenital anomalies involving both intestinal and extra intestinal regions like congenital heart disease, preoperative radiologic findings, surgical procedures performed, site of perforation, size of perforation, clinical outcome, and surgical complications were collected on a predesigned pro forma. Suspected patients were excluded who did not undergo exploration. All the recorded data was analyzed by SPSS 26 (version 233 South Wacker Drive, 11th Floor Chicago, IL 60606-6307 USA).

Qualitative variable was presented as mean SD, and for quantitative variables, we calculated as percentages and frequency.

\section{Results}

A total of 46 neonates were included. Male gender predominated with M:F being 1.7:1. Most of them were full term (69.6\%). Twenty patients were having weight less than $2.5 \mathrm{~kg}$, and $5 \mathrm{had}<2 \mathrm{~kg}$ weight. About $60.9 \%$ ( $n=$ 28) were delivered by caesarian section. The history of neonatal asphyxia prior to presentation was found in only $10(21.7 \%)$ patients while none had history of mechanical ventilation, but 11 (23.9\%) remained admitted in intensive care unit. Nasogastric tube was attempted in 14 (30.4\%) neonates before admission. Three neonates (6.5\%) had associated congenital heart disease, two had duodenal atresia, two with respiratory distress, and eight neonates had associated perinatal factors. Feeding was already started in 37 neonates, and 43.5\% $(n=20)$ were given formula feed; however, no feeding was started in 9 neonates. Most $(n=38)$ neonates presented within 10 days of life whereas 8 neonates came within 15 days. At presentation, gas under diaphragm was the most common radiologic finding in 25 (54.3\%) neonates, out of which 6 patients had typical food ball sign (Fig. 1). The demographic and clinical details are summarized in Table 1.

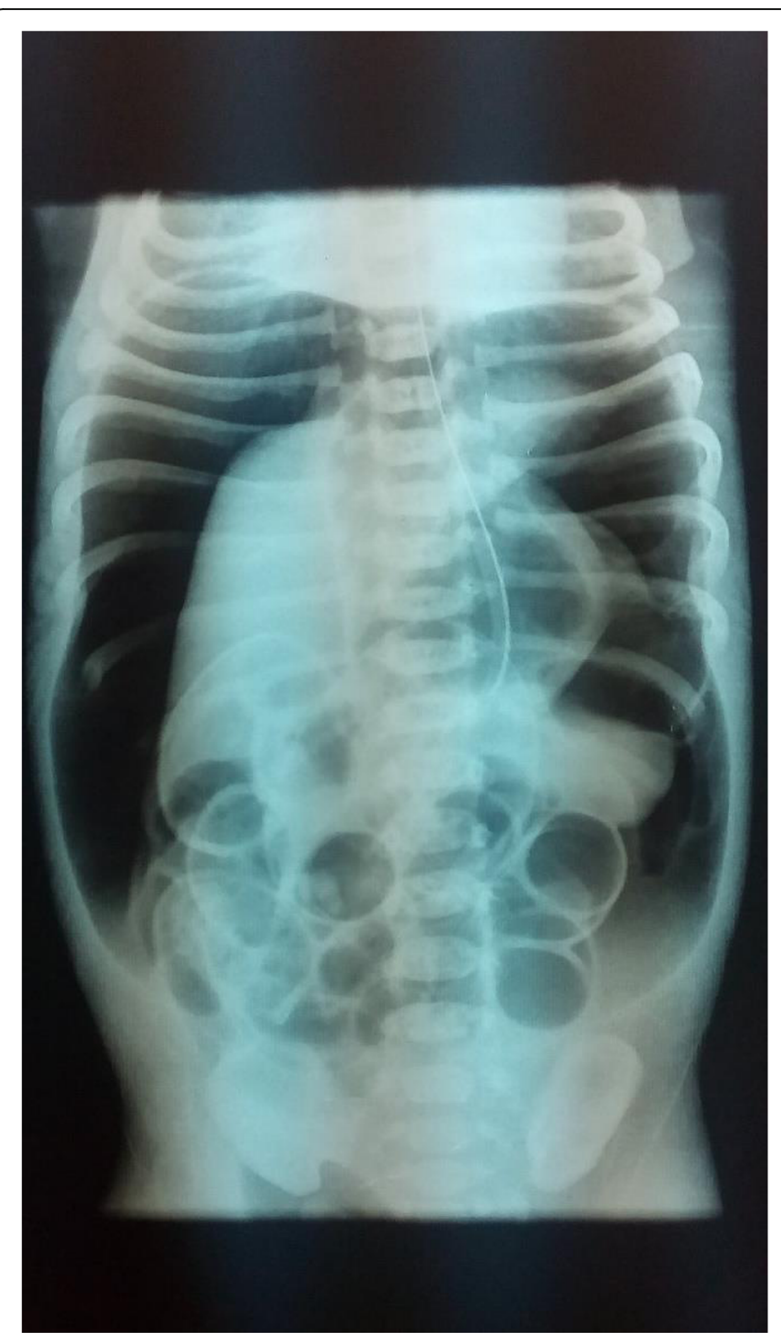

Fig. 1 Football sign in a neonate with gastric perforation

An early management for optimization of neonates includes either laparostomy tube placement followed by laparotomy or if already optimized then directly underwent for laparotomy. On exploratory laparotomy, it was found that greater curvature was involved in most cases $(n=27)$, followed by lesser curvature and anterior and posterior walls of the stomach. Most perforations were $1-5 \mathrm{~cm}$ in size. Gastrorrhaphy was done in all cases, and in two cases, feeding jejunostomy was done along with repair for feeding purpose. Finally spontaneous NGP was diagnosed in $30(60.8 \%)$ whereas no obvious cause elucidated on exploration, thus revived diagnosis label NGP. Due to associated NEC patches on other parts of the intestine, 11 neonates were labelled having NECassociated NGP. Three had findings similar to ischemic type and two cases to traumatic NGP. Details are given in Table 2.

Postoperatively, a total of 28 neonates developed complications in the form of sepsis $(n=13)$, wound infection 
Table 1 Demographic and clinical details of patients $(n=46)$

\section{Characteristics}

Gender

Male

Female

Gestational age

Full term (> 36 weeks)

Preterm (33-36 weeks)

Mode of delivery

C section

Normal vaginal delivery

Birth weight $(\mathrm{kg})$

Normal $(2.6-4.0 \mathrm{~kg})$

Low birth weight $(2.5-2.0 \mathrm{~kg})$

Extremely low birth weight $(<2 \mathrm{~kg})$

Neonatal asphyxia prior to presentation

Mechanical ventilation prior to perforation

Nasogastric tube insertion prior to perforation

Neonatal ICU admission prior to perforation

Associated congenital heart disease

Associated duodenal atresia

Associated respiratory distress

Associated NEC

Antenatal/perinatal risk factor

Premature rupture of membranes $>24 \mathrm{~h}$

Premature rupture of membranes $<24 \mathrm{~h}$

Pregnancy-induced hypertension

Per vaginal bleeding for 4 months

Oligohydramnios

Maternal diabetes + age $>40$ years

Feeding

No

Yes

Bottle feed

Mother feed

Cow's milk

Radiologic findings

Gas under diaphragm

Football sign

Rigler's sign

Cupola sign
Number of patients (\%)

17 (37)

32 (69.6)

$14(30.4)$

18 (39.1)

25 (54.4)

16 (34.8)

5 (10.9)

$10(21.7)$

0

14 (30.4)

11 (23.9)

$3(6.5)$

2 (4.3)

2 (4.3)

9 (19.6)

8 (19.3)

$2(4.9)$

2 (4.9)

1 (2.4)

1 (2.4)

1 (2.4)

1 (2.4)

9 (22)

37 (78)

20 (43.5)

10 (21.7)

7 (15.2)

$25(54.3)$

6 (34.8)

$3(6.5)$

2 (4.3) $(n=10)$, and burst abdomen $(n=5)$. Regarding clinical outcome, 27 (58.7\%) were discharged from hospital; overall mortality was 19 (41.3\%). Details are shown in Table 3.

\section{Discussion}

Our study population consisted of 29 males and $17 \mathrm{fe}$ males with ratio of $\mathrm{M}: \mathrm{F}=1.7: 1$. Gupta et al. and Kara et al. showed different results with gender distribution. 
Table 2 Surgical findings and operative details of patients

\begin{tabular}{ll}
\hline Operative details & Number of patients (\%) \\
\hline Site of perforation & $27(58.7)$ \\
Greater curvature & $13(28.3)$ \\
Lesser curvature & $3(6.5)$ \\
Anterior wall of stomach & $3(6.5)$ \\
Posterior wall of stomach & \\
Size of perforation (cm) & $27(58.7)$ \\
$1-5$ & $17(37.0)$ \\
$6-10$ & $2(4.3)$ \\
$11-15$ & \\
Possible cause of perforation & $28(60.9)$ \\
Spontaneous GP & $14(30.4)$ \\
NEC-associated GP & $2(4.3)$ \\
Ischemic GP & $2(4.3)$ \\
Traumatic & \\
Surgical procedures & $44(95.7)$ \\
Gastrorrhaphy & $2(4.3)$ \\
Gastrorrhaphy + feeding gastrostomy &
\end{tabular}

They reported NGP being four times commoner in males than females $[6,11]$. We found that $69.6 \%$ neonates were full term and $30.4 \%$ were born between 33 and 36 weeks of gestation whereas a large number of neonates $(n=22)$ had weight less than 2.5. Similar percentage was noted by Kara et al. in neonates with gastric perforation [6]. Byun et al. also reported that NGP is common in full-term neonate [12]. According to our results, most neonates with NGP were just presented within 10 days of life (78\%), and only one patient presented late after 20 days. This finding was compared with Kara et al. and Byun et al. $[6,12]$

Leone and Krasna reported that 4 out of 7 neonates had pre-existing cause while 3 had no identifiable cause of NGP [7]. In literature, the etiology of NGP is still debatable though many suggested causes like congenital weakness or absence of muscle [13], high gastric acidity leading to ulceration [14], trauma to gastric wall [15],

Table 3 Postoperative events in patient

\begin{tabular}{ll}
\hline Post-operative complications & Number of pt.'s (\%) \\
\hline No & $18(39.1)$ \\
Yes & $28(60.9)$ \\
Sepsis & $13(28.3)$ \\
Wound infection & $10(21.7)$ \\
Burst abdomen & $5(10.9)$ \\
Outcome & \\
Discharge & $27(58.7)$ \\
Mortality & $19(41.3)$ \\
\hline
\end{tabular}

neonatal asphyxia causing intestinal ischemia [16], raised intragastric pressure caused by swallowing of air or distal obstruction [17, 18], and lack of intestinal pacemaker cells [19] or C-KIT + mast cells [20]. Usually, the mixture of causes is proposed as far as etiology of NGP is concerned [21], and the most common cause was found to be the raised intragastric pressure causing rupture of the stomach wall usually in a dilated stomach and uncoordinated vomiting due to poor neurologic control [8, 18]. We reported spontaneous NGP in 30 neonates as no obvious and clear cause was found; associated NEC patches were seen in 11 neonates, three had findings suggestive of ischemic insult, and two cases were due traumatic injury. One hypothesis is that spontaneous perforations are due to the congenital defects in the muscular wall of the stomach [22]. In our study, 10 neonates had a history of neonatal asphyxia at birth and neonatal ICU admission which we suspect may be the cause of intestinal ischemia and perforation. In 14 cases, there was history of pre-admission NG placement, but only two cases of NGP found per-operatively to have features of traumatic type. Three of our cases had associated congenital heart diseases and had per-operative findings of ischemic variety of perforation. Two cases having duodenal atresia lead to raise intra-gastric. Regarding clinical outcome, 27 (58.7\%) patients were discharged after recovery; 17 (39.3\%) neonates died including five cases who left against medical advice. Despite all advances in neonatal pre- and post-operative care throughout literature, mortality rate associated with NGP is still very high. Leone and Krasna reported 70\% mortality rate [7]. However, in a recent study by Yang et al. [19], mortality rate decreased with improvement in neonatal care; they divided study neonates into four groups, i.e., 1980-1989, 1990-1999, 2000-2009, and 2010-2016, and reported mortality for the four groups was $(5 / 5) 100 \%,(12 / 24) 50 \%,(6 / 19) 31.6 \%$, and $(3 / 18)$ $16.7 \%$, respectively.

\section{Conclusion}

Our results show that spontaneous NGP is most commonly associated with NEC in our population, usually affecting the greater curvature. We observed a high mortality rate; however, good ICU care may improve the survival.

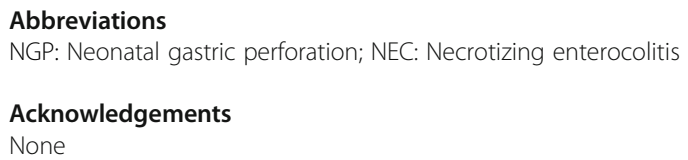

Authors' contributions

All of the following authors have read and approved the manuscript. I $\mathrm{H}$ : synopsis writing, data collection. NT: supervisory. A I: manuscript writing. M S C: supervisory role. $\mathrm{N} \mathrm{H}$ : data analysis. S I N: data collection. M S: study design. A R W: supervisory. S A: supervisory. 


\section{Funding}

Author has no funding source regarding this study.

\section{Availability of data and materials}

All the data of patients along with data sheet is available and can be provided on request from editor.

\section{Ethics approval and consent to participate}

Ethical approval was taken from IBR of Children Hospital Lahore (Reference No.CHICH 9/18). Oral consent was taken from parents, and it was approved by ethical committee. I also give consent to participate.

\section{Consent for publication}

Not applicable

\section{Competing interests}

The authors declare no competing interests.

\section{Author details}

'Department of Pediatric Surgery, The Children Hospital \& The Institute of Child Health, Lahore, Pakistan. 'Department of Pediatric Surgery, Dera Ghaz Khan Medical College, Dera Ghazi Khan, Pakistan. ${ }^{3}$ Department of Pediatric Surgery, The King Edward Medical University, Lahore, Pakistan. ${ }^{4}$ Department of Pediatric Surgery, Jinnah Hospital Lahore, Lahore, Pakistan. ${ }^{5}$ Department of Pediatric Surgery, The Children Hospital \& ICH Faisalbad, Faisalabad, Pakistan.

Received: 6 August 2020 Accepted: 15 February 2021

Published online: 12 May 2021

\section{References}

1. Linkner $L M$, Benson CD. Spontaneous perforation of the stomach in the newborn; analysis of thirteen cases. Ann Surg. 1959;149:525-33.

2. St-Vil D, LeBouthillier G, Luks Fl, Bensoussan AL, Blanchard H, Youssef S. Neonatal gastrointestinal perforations. J Pediatr Surg. 1992;27:1340-2.

3. Rosser SB, Clark CH, Elechi EN. Spontaneous neonatal gastric perforation. J Pediatr Surg. 1982;17:390-4.

4. Holgersen LO. The etiology of spontaneous gastric perforation of the newborn: a reevaluation. J Pediatr Surg. 1981;16:608-13.

5. Tan CE, Kiely EM, Agrawal M, Brereton RJ, Spitz L. Neonatal gastrointestinal perforation. J Pediatr Surg. 1989;24:888-92

6. Kara CS, Ilçe Z, Celayir S, Sarimurat N, Erdogan E, Yeker D. Neonatal gastric perforation: review of 23 years' experience. Surg Today. 2004;34:243-5.

7. Leone RJ, Krasna IH. 'Spontaneous' neonatal gastric perforation: is it really spontaneous? J Pediatr Surg. 2000;35:1066-9 https://doi.org/10.1053/jpsu.2 000.7773 .

8. Jawad AJ, Al-Rabie A, Hadi A, Al-Sowailem A, Al-Rawaf A, Abu-Touk B, AlKarfi T, Al-Sammarai A. Spontaneous neonatal gastric perforation. Pediatr Surg Int. 2002;18:396-9.

9. Chung MT, Kuo CY, Wang JW, Hsieh WS, Huang CB, Lin JN. Gastric perforation in the neonate: clinical analysis of 12 cases. Zhonghua Minguo Xiaoerke Yixuehui Zazhi. 1994;35:460-5.

10. Lin CM, Lee HC, Kao HA, Hung HY, Hsu CH, Yeung CY, Sheu JC, Wang NL. Neonatal gastric perforation: report of 15 cases and review of the literature. Pediatr Neonatol. 2008:49:65-70.

11. Malhotra-Gupta G, Janowski C, Sidlow R, et al. Gastric perforation secondary to a trichobezoar: a case report and review of the literature. J Pediatr Surg Case Reports. 2017;26:11-4 https://doi.org/10.1016/j.epsc.2017.08.014.

12. Byun J, Kim HY, Noh SY, et al. Neonatal gastric perforation: a single center experience. World J Gastrointest Surg. 2014;6:151-5 https://doi.org/10.4240/ wjgs.v6.18.151.

13. Zet Z, Darmawan S, Kartono D. Congenital defect in the musculature of the stomach with spontaneous rupture in a newborn infant. Paediatr Indones. 2017;14:106 https://doi.org/10.14238/pi14.5-6.1974.106-108.

14. Kiesewetter WB. Spontaneous rupture of the stomach in the newborn. Arch Pediatr Adolesc Med. 1956;91:162 https://doi.org/10.1001/archpedi.1956.02 060020164013.

15. Arnold GG. Perforation of the stomach in the neonatal period; report of a survival in a premature infant. J Pediatr. 1955:46:276-9.

16. Touloukian RJ, Posch JN, Spencer R. The pathogenesis of ischemic gastroenterocolitis of the neonate: selective gut mucosal ischemia in asphyxiated neonatal piglets. J Pediatr Surg. 1972;7:194-205.
17. James AE, Heller RM, White JJ, et al. Spontaneous rupture of the stomach in the newborn: clinical and experimental evaluation. Pediatr Res. 1976;10:7982 https://doi.org/10.1203/00006450-197602000-00001.

18. Houck WS, Griffin JA. Spontaneous linear tears of the stomach in the newborn infant. Ann Surg. 1981;193:763-8.

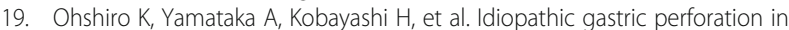
neonates and abnormal distribution of intestinal pacemaker cells. J Pediatr Surg. 2000;35:673-6 https://doi.org/10.1053/jpsu.2000.5940.

20. Yamataka A, Yamataka T, Kobayashi H, et al. Lack of C-KIT+ mast cells and the development of idiopathic gastric perforation in neonates. J Pediatr Surg. 1999;34:34-7 discussion 37-8.

21. Pelizzo G, Dubois R, Lapillonne A, et al. Gastric necrosis in newborns: a report of 11 cases. Pediatr Surg Int. 1998;13:346-9.

22. Yang T, Huang Y, Li J, et al. Neonatal gastric perforation: case series and literature review. World J Surg. 2018:42:2668-73 https://doi.org/10.1007/s002 $68-018-4509-x$

\section{Publisher's Note}

Springer Nature remains neutral with regard to jurisdictional claims in published maps and institutional affiliations.

\section{Submit your manuscript to a SpringerOpen ${ }^{\circ}$ journal and benefit from:}

- Convenient online submission

- Rigorous peer review

- Open access: articles freely available online

- High visibility within the field

- Retaining the copyright to your article

Submit your next manuscript at $\boldsymbol{\nabla}$ springeropen.com 